\title{
IMPACT OF HEMODIALYSIS ON PATIENT'S LIVELIHOOD IN FAISALABAD PUNJAB PAKISTAN.
}

1. Ph.D Scholar Administrator

Ali Zaib Foundation Faisalabad.

2. Post Doc.

Professor/Head of Sociology GCUF.

3. MBBS

Medical Officer

Naila Medical Center Faisalabad.

4. Ph.D Scholar

Director

Just One Enterprises Faisalabad.

5. MBBS (KE)

Diploma Cardiology (London), FACC (USA)

Consultant

Department of Cardiologist

Khadija Memorial Hospital,

Faisalabad.

Correspondence Address:

Dr. Aqib Rehman

Naila Medical Center Faisalabad.

aqib2517@gmail.com

Article received on:

02/02/2019

Accepted for publication:

24/06/2019

\begin{abstract}
Muhammad Nafees ${ }^{1}$, Zahira Batool ${ }^{2}$, Aqib Rehman ${ }^{3}$, M. Rizwan Ashraf ${ }^{4}$, Habib Aslam Gaba ${ }^{5}$
\end{abstract}
\begin{abstract}
Hemodialysis adversely affects many dimensions of the patients. So this study was carried out to assess the impact of hemodialysis on livelihood of the patients. Objectives: To study the socio-economic characteristics of Hemodialysis (HD) dependent patients, to explore the impact of hemodialysis on the livelihood of the patients, and to suggest some suitable policy measures. Study Design: Cross sectional study. Setting: At Dialysis Center of DHQ Hospital Faisalabad, Punjab, Pakistan. Period: May 2018 November 2018. Material \& Methods: Multistage sampling technique was used, at $1^{\text {st }}$ step a public sector dialysis center was selected through simple random sampling and then 109 adult patients were conveniently selected and interviewed through self-designed interview schedule. Data analysis and interpretation was executed using (SPSS version 24). Multiple linear regression was applied to study the relevant significance of predicting variables and to check the impact of different variables on respondent's livelihood (response variable). Conclusion: It was found that due to rigorous schedule of HD most of the respondents were unable to perform their economic, social and religious activities; also they were depending on their caregivers for their routine activities. Resultantly, lower SES (socio-economic) has a negative effect on health in patients with undergoing dialysis involving fewer personal resources and lower levels of social support to deal with stress imposed by HD. Hence HD was negatively affecting their livelihood, so there is dire need to address these problems of HD dependent segment.
\end{abstract}

Key words: $\quad$ End Stage Renal Disease, Hemodialysis, Livelihood.

Article Citation: Nafees M, Batool Z, Rehman A, Ashraf MR, Gaba HA. Impact of Hemodialysis on patient's livelihood in Faisalabad Punjab Pakistan. Professional Med $\mathrm{J}$ 2019; 26(12):2100-2104. DOI: 10.29309/TPMJ/2019.26.12.3209

\section{INTRODUCTION}

CKD has become a public health problem all over the world with extreme incidence in the Asian countries and its burden is quickly enhancing all over the world..$^{1,2,3}$ If CKD is not treated, it converts into ESDR where the patient have only two options for survival i.e dialysis, and/ or kidney transplant. Hemodialysis (HD) is credited with the most familiar method of dialysis as to United States Renal Data System. In Pakistan the prevalence of ESRD is at peak among the masses due to the high incidence of hypertension and diabetes. ${ }^{4}$ Dialysis treatment or kidney transplant creates a massive economic burden for most of the patients in the middle income countries. In other 112 countries a large number of patients are unable to afford renal replacement therapy which causes the mortality of more than one million people per year. ${ }^{5}$ The patients referred to hemodialysis require a lot of time that decreases their time for social events and leisure. ${ }^{6}$ Although lifesaving but HD comprises of many adverse outcomes that decline the livelihood of its dependents. ${ }^{7}$ This study was designed to study the socio-economic background of hemodialysis patients and to study impact of hemodialysis on livelihood of the respondents.

\section{OBJECTIVES}

1. To study the socio-economic characteristics of Hemodialysis (HD) dependent patients.

2. To explore the impact of hemodialysis on the livelihood of the patients.

3. To suggest some suitable policy measures.

METHODOLOGY

The population in this study was all adults diagnosed ESRD patients receiving HD in public 
sector dialysis centers in Faisalabad. Multistage sampling was used. Dialysis center of DHQ Hospital Faisalabad was randomly selected from three public sector dialysis centers of Faisalabad. Afterward 109 participants were selected conveniently for data collection using selfdesigned interview schedule. Patients diagnosed with ESRD receiving HD treatment for more than 1 year and aged 18 years or more were recruited to collect responses. 4 experts (One nephrologist, one senior medical officer, one head nurse and one sociologist) having broad experience of dealing with patients of ESDR, and research were consulted to make certain that interview schedule was consists of appropriate items to be represent. It was modified according to their recommendations and also after conducting a pilot study test on ten respondents. Data was analyzed through Statistical Package for Social Sciences version 24 (SPSS) using Univariate, bivariate and multivariate statistic techniques. Multiple linear regression was applied by the researchers to study the relevant significance of predicting variables and also to check the impact of different independent variables on respondent's livelihood (dependent variable).

\section{RESULTS AND DISCUSSIONS}

Socioeconomic status is the class or social standing of individual or the group that is often its measurement is based on the combination of occupation, income and education. Study of socioeconomic status often expose inequalities in accessing resources, and problems linked with power, control and privilege. ${ }^{8}$

The socioeconomic background of the respondents is expressed in Table-I.

Data illustrates that 56.9 percent respondents were male and 43.1 percent were female, 56.0 percent belonged to rural areas compared to 44.0 percent from urban areas. Majority of respondents 38.5 percent were from age group 32 to 46 years followed by 35.8 percent from 47 to 60 years, 21.1 percent above 60 years, and 4.6 percent from the group 18 to 31 years. 55.0 percent respondents had monthly household income up to Rs. 15,000 PKR, 30.3 percent from 15,001 to 30,000 PKR,
7.3 percent from 30,001 to 45,000 PKR and same number of respondents above 45,000 PKR. Also 73.4 percent respondents were got into debt since the start of hemodialysis.

To explore the socio-economic, physical, psychological and morbid impact of hemodialysis on patients' livelihood, a compound variable was designed by the researchers. The responses from the respondents accordingly are shown in Table-Il.

Many respondents were needed assistance for their dialysis and routine activities. Rigorous schedule of dialysis was restricting them to continue their jobs and other economic activities as a result, their ability to purchase the medicine was declining and they were forced to start selling their assets. Muehreret al. $(2011)^{9}$ also mentioned that unemployment was the reason of psychological and physical problems like depression, sexual dysfunction and anxiety. Also unemployment create additional economic problems and with the passage of time they start to sale their assets. Bulk of respondents were unable to perform their religious activities also their social life was adversely affected and they were feeling stressed due to such changes in their life. Many respondents reported that formal education of their children was affected. Loss of economic sources along with treatments costs worsen their already poor physical, economic, and psychological conditions.

Through multiple linear regression analysis, researchers analyzed the impact of various variables on respondent's livelihood. Table-III shows the Standardized Coefficients Beta, "t" score and significance of each variable.

In this analysis the researcher asked male as option No. 1, and female as option No. 2 so the Regression coefficient value of "Gender" X1 of -0.201 shows that livelihood of female respondents was 0.201 units more affected than that of the male respondents. 


\begin{tabular}{|c|c|c|}
\hline Socio-economic Characteristics & Frequency & Percentage \\
\hline \multicolumn{3}{|l|}{ Gender } \\
\hline Male & 62 & 56.9 \\
\hline Female & 47 & 43.1 \\
\hline \multicolumn{3}{|l|}{ Residential Area } \\
\hline Rural & 61 & 56.0 \\
\hline Urban & 48 & 44.0 \\
\hline \multicolumn{3}{|l|}{ Age Group } \\
\hline 18 to 31 & 5 & 4.6 \\
\hline 32 to 46 & 42 & 38.5 \\
\hline 47 to 60 & 39 & 35.8 \\
\hline Above 60 & 23 & 21.1 \\
\hline \multicolumn{3}{|l|}{ Monthly Household income } \\
\hline Up to Rs. 15,000 & 60 & 55.0 \\
\hline Rs. 15,001 to Rs. 30,000 & 33 & 30.3 \\
\hline Rs. 30,001 to Rs. 45,000 & 8 & 7.3 \\
\hline Rs. 45,001 and above & 8 & 7.3 \\
\hline \multicolumn{3}{|l|}{ Respondents get into debt } \\
\hline Yes & 80 & 73.4 \\
\hline No & 29 & 26.6 \\
\hline
\end{tabular}

\begin{tabular}{|l|c|c|c|c|c|c|}
\hline \multicolumn{1}{|c|}{ Statement } & \multicolumn{2}{|c|}{ To a greater extent } & To some extent & \multicolumn{2}{c|}{ Not at all } \\
\hline & Freq & \%age & Freq & $\%$ age & Freq & $\%$ age \\
\hline $\begin{array}{l}\text { Need to be assisted by someone for dialysis and routine } \\
\text { activities }\end{array}$ & 16 & 14.7 & 88 & 80.7 & 5 & 4.6 \\
\hline Routine dialysis schedule affected economic activities & 86 & 78.9 & 23 & 21.1 & 0 & 0.0 \\
\hline Ability to purchase medicines & 43 & 39.5 & 6 & 5.5 & 60 & 55.0 \\
\hline $\begin{array}{l}\text { Assets (such as car, bike, bicycle, house, television, piece of } \\
\text { land, livestock) sold for the medical treatment }\end{array}$ & 35 & 32.1 & 6 & 5.5 & 68 & 62.4 \\
\hline Social life affected & 87 & 79.8 & 18 & 16.5 & 4 & 3.7 \\
\hline Religious activities affected & 18 & 16.5 & 87 & 79.8 & 4 & 3.7 \\
\hline Routine dialysis create stress & 85 & 77.9 & 21 & 19.3 & 3 & 2.8 \\
\hline Routine dialysis schedule affect formal education of children & 23 & 21.1 & 45 & 41.3 & 41 & 37.6 \\
\hline
\end{tabular}

Table-II. Impact of hemodialysis on patients' livelihood

\begin{tabular}{|c|l|c|c|c|}
\hline Sr \# & \multicolumn{1}{|c|}{ Variables } & $\begin{array}{c}\text { Standardized } \\
\text { Coefficients Beta }\end{array}$ & T & Sig. \\
\hline 1 & Gender $\mathrm{X}_{1}$ & -0.201 & -3.040 & 0.003 \\
\hline 2 & Monthly household income $\mathrm{X}_{2}$ & 0.212 & 2.625 & 0.010 \\
\hline 3 & Since the start of dialysis, respondents get into debt? $\mathrm{X}_{3}$ & 0.263 & 2.773 & 0.007 \\
\hline 4 & Residential area $\mathrm{X}_{4}$ & 0.184 & 2.349 & 0.021 \\
\hline 5 & Distance of dialysis center from respondents' residence. $\mathrm{X}_{5}$ & -0.191 & -2.777 & 0.007 \\
\hline 6 & $\begin{array}{l}\text { Satisfaction level of the respondents with facilities being } \\
\text { provided by dialysis center X }\end{array}$ & -0.190 & -2.415 & 0.018 \\
\hline
\end{tabular}


Armaly et al. (2012) ${ }^{10}$ also found the incidence of depression more in females compared to the male hemodialysis dependent patients. $t$ score of monthly household income $\left(X_{2}\right)$ is 0.212 which means that increase of Rs.1,000/-PKR monthly household income can increase 0.212 units of their livelihood. A previous study by Patzer RE \& McClellan WM (2012) ${ }^{11}$ also concluded that ESRD usually affects patients having lower incomes.

Due to their inability to participate in the paid work many respondents borrow money from their friends, relatives and banks. $X_{3}$ shows the impact of debt on the livelihood of the respondents and its $t$ score 0.263 means that 0.263 units of livelihood of a respondents is affected when he get into debt.

$\mathrm{X}_{4}$ represent the impact of residential area on respondents livelihood where $t$ score0.184 shows that livelihood of rural respondents was 0.184 units more affected than the respondents from urban areas. Anees, M et al., (2014) ${ }^{12}$ also found that residence in rural areas along with other factors affect the quality of life among these patients. $t$ score of distance of the dialysis center from respondents' residence $\left(X_{5}\right)$ was -0.191 which reveals that increase in the one unit of distance between the respondents' residence and the dialysis center will decrease 0.191 units of the livelihood of the respondents. A study by Moist et al. $(2008)^{13}$ reveals that these patients face long traveling times, that is linked with worse mortality. $\mathrm{X}_{6}$ reflects the impact of "satisfaction of the respondents with facilities provided by the dialysis center" on their livelihood. its $t$ score -0.190 shows that one unit of satisfaction level of the respondents affect 0.190 units of the livelihood of the respondents at significance level of 0.018 . It reflects that the satisfaction level of the respondents significantly affecting their livelihood.

\section{CONCLUSION}

It was found that most of the HD dependents were unable to continue their economic activities due to rigorous schedule of their dialysis. Many of the respondents got into debt since the start of their dialysis. Moreover they were depending on their caregivers for accomplishment towards dialysis center and to fulfill other routine activities. Also they were unable to performing their religious practices. In this way Hemodialysis was negatively affecting the livelihood of the respondents in connection with its effect on their economic, social, physical and psychological health. Regression analysis shows that the livelihood of female respondents was more affected compared to the male respondents, also lack of income, pressure of debt, rural residential area, distant residence from the dialysis center, and lack of facilities provided by the dialysis center were adversely affecting the livelihood of the respondents. So there is dire need to address these problems of HD dependents. There is dire need to address the problems of these patients. It might be an alternative approach of curing these patients or it may be relaxation/ necessary amendments in the rules of living kidney donor transplant.

\section{RECOMMENDATIONS}

- There is need to increase the number of public sector dialysis centers.

- Pick and drop facility through ambulances may be allocated to them on zero cost.

- Provision of more nursing staff in the dialysis center can minimize the need of assistance of their caregivers.

- There is need to invent a new mode of therapy because the hemodialysis constrain its dependents to live a life with no or little participation in economic activities and dependency on the other members of the society. Weisbord et al. (2007a) ${ }^{14}$ also mentioned that HD does not treat ESRD, it just allow the patient to survive. There should be a portable dialyzer that can be used at home or workplace by the patients, and it should also be available on low prices. In this way the patient will be able to continue his/ her economic activities.

\section{Copyright@ 24 June, 2019.}

\section{REFERENCES}

1. Jha V, Garcia-Garcia G, Iseki K, Li Z, Naicker S, Plattner $B$, et al. (2013) Chronic kidney disease: global dimension and perspectives. Lancet. Jul 20 2013; 382(9888):260-272. 
2. Farhad Hosseinpanah, Farshad Kasraei, Amir A Nassiri, Fereidoun Azizi,. High prevalence of Chronic Kidney Disease in Iran: A large population-based study. BMC Public Health 2009; 9:44.

3. Anand S, Bitton A, Gaziano T. The gap between estimated incidence of end-stage renal disease and use of therapy. PLoS One. 2013 Aug 30;8(8):e72860.

4. Tamizuddin S, Ahmed W. Knowledge, attitude and practices regarding chronic kidney disease and estimated GFR in a tertiary care hospital in Pakistan. JPMA. The Journal of the Pakistan Medical Association. 2010 May 1;60(5):342-46

5. Couser WG, Remuzzi G, Mendis S, Tonelli M. The contribution of chronic kidney disease to the global burden of major noncommunicable diseases. Kidney international. 2011 Dec 2;80(12):1258-70.

6. Finnegan-John J, Thomas VJ. The psychosocial experience of patients with end-stage renal disease and its impact on quality of life: findings from a needs assessment to shape a service. ISRN nephrology. 2012 Oct $21 ; 2013$.

7. Gerogianni S, Babatsikou F, Gerogianni G, Koutis C, Panagiotou M, Psimenou E. Social life of patients undergoing haemodialysis. International Journal of Caring Sciences. 2016 Jan 1;9(1):122.

8. APA's socioeconomic status office publications (https://www.apa.org/topics/socioeconomic-status/).
9. Muehrer RJ, Schatell D, Witten B, Gangnon R, Becker $\mathrm{BN}$, Hofmann RM. Factors affecting employment at initiation of dialysis. Clinical Journal of the American Society of Nephrology. 2011 Mar 1;6(3):489-96.

10. Armaly Z, Farah J, Jabbour A, Bisharat B, Abd-El Qader A, Saba S, Zaher M, El Haj E, Hamzi M, Bowirrat A. Major depressive disorders in chronic hemodialysis patients in Nazareth: identification and assessment. Neuropsychiatric disease and treatment. 2012;8:329.

11. Patzer RE, McClellan WM. Influence of race, ethnicity and socioeconomic status on kidney disease. Nature Reviews Nephrology. 2012 Sep;8(9):533.

12. Anees M, Malik MR, Abbasi T, Nasir Z, Hussain Y, Ibrahim $M$. Demographic factors affecting quality of life of hemodialysis patients-Lahore, Pakistan. Pakistan journal of medical sciences. 2014 Sep;30(5):1123. http://doi.org/10.12669/pjms.305.5239.

13. Moist LM, Bragg-Gresham JL, Pisoni RL, Saran R, Akiba T, Jacobson SH, Fukuhara S, Mapes DL, Rayner $\mathrm{HC}$, Saito A, Port FK: Travel time to dialysis as a predictor of health-related quality of life, adherence, and mortality: The Dialysis Outcomes and Practice Patterns Study (DOPPS). Am J Kidney Dis51: 641650, 2008.

14. Weisbord, S.D., Fried, L.F., Mor, M.K., Resnick, A.L., Kimmel, P.L., Palevsky, P.M., et al. (2007a). Associations of race and ethnicity with anemia management among patients initiating renal replacement therapy. J Natl Med Assoc, 99, 1218-1226.

\begin{tabular}{|c|c|c|c|}
\hline \multicolumn{4}{|c|}{ AUTHORSHIP AND CONTRIBUTION DECLARATION } \\
\hline Sr. \# & Author(s) Full Name & Contribution to the paper & Author(s) Signature \\
\hline 1 & Muhammad Nafees & Write up, Analysis of data. & \\
\hline 2 & Zahira Batool & Write up, Analysis of data. & \\
\hline 3 & Aqib Rehman & $\begin{array}{l}\text { Data collection, Review of } \\
\text { literature. }\end{array}$ & \\
\hline 4 & M. Rizwan Ashraf & $\begin{array}{l}\text { Theoretical framework, Data } \\
\text { Collection, Proof Reading. }\end{array}$ & \\
\hline 5 & Habib Aslam Gaba & $\begin{array}{l}\text { Review of literature, Proof } \\
\text { reading. }\end{array}$ & \\
\hline
\end{tabular}

